\section{No PWR, thanks}

SIR - The leading article "Inventing the wheel" (Nature 300, 672; 1982) about the rights and wrongs of holding a public inquiry into the possibility of a Sizewellbased pressurized water reactor (PWR) seemed to be derived from information received from the top of Mt Sinai to which the rest of us are not privy. In singling out the Friends of the Earth, or any other member of the opposition to the Central Electricity Generating Board's (CEGB's) proposals, for a rather sneering attack, the writer of the article demonstrated all the sporting sensibilities of a piranha. The opposition to PWRs is widespread and finds its voice through a number of mainly poor subscribed to organizations like the Friends of the Earth. The fact the opposition collectively and individually is fiscally improverished, however, should not be confused with the intellectual merits of the opposition's many and frequently very disturbing arguments. These arguments relate not only to safety but to economics and conservation issues also. The inquiry is interested in Sizewell not on its own but in the context of a very expensive commitment to a national nuclear power programme.

With reference to the economics of the case alone, three independent bodies have been severely critical of the CEGB's projections. These are the House of Commons Select Committee on Energy, the Monopolies and Mergers Commission and the Electricity Consumers' Council. In addition, there has also been criticism of safety aspects of the proposed Sizewell PWR by the Nuclear Installations Inspectorate. Surely there is a benefit to be accrued from a public forum where the CEGB may be seen to answer such powerful critics.

I must confess I prefer this approach, for example, to the empirical one on the safety aspect advocated in your article where it is recommended that we build a PWR to see what, if any, the dangers are. I have a particular reason to reject this argument as I live in Winfrith, Dorset, in the vicinity of a site under consideration by the CEGB for a future PWR. I wonder if the writer of the editorial would be such a powerful advocate of the empirical method if he lived in my neighbourhood.

BARRIE PEARSON Winfrith, Dorset, UK

\section{Generic prescribing}

SIR - Your report on UK drug prescriptions (Nature 17 February, p.557) seems to overlook the fact that generic prescribing has been taught to medical students by university departments of pharmacology and therapeutics for at least 30 years.

Moreover, the Department of Health and Social Security regularly distributes free of charge comparative bar-charts showing very clearly the relative costs per unit of active principle of the different drug preparations with the same therapeutic action which are available, so there is really no excuse for doctors being unaware of the economics of prescribing.

Why, then, do they not choose the most economic alternative? Certainly relative assonance or dissonance of the name has some influence. The commercial designer of a drug always gets in first with his proprietary name, long before the approved name is devised, and here it is the case that the devil gets all the best tunes. I must confess to finding that the proprietary "Chloromycetin" comes to mind more readily than the approved "chloramphenicol", for instance.

Perhaps the effect of real differences in efficacy and efficiency between different preparations of the same drug has been under-estimated. It is well known that the efficiency and efficacy of drugs is critically dependent on pharmaceutical formulation and process technology. It is in this sphere that most scope exists for differences between the products of different drug firms, and prescribing doctors, who have to live with their therapeutic failures as well as their successes, are not as susceptible to commercial blandishments as BBC television's "Panorama" team would have us believe. They may be expected to choose the preparation which they think will most benefit their patients - perhaps on very limited evidence.

What is needed is very much more attention, at ministry level, to comparative studies of efficacy, rather than active principle content, in relation to cost. If such information were more readily available, it might be expected not only to stimulate rational and cost-conscious prescribing, but also to stimulate the drug firms to produce products which represent real advances on those of their competitors. R.J. ANCILL Pharmacology Department, University of Bath, UK

\section{Tank makers note:}

SIR - As an opponent of the neutron bomb, I welcome the calculations of Seifritz et al. (Nature 299, 390; 1982), from which a specification for a practical radiation shield for tanks can be derived.

In the following calculations, the shield is described as $\mathrm{g} \mathrm{cm}^{-2}$ (taking weight as the limiting factor) and the weight is kept within the limits adopted by Seifritz et al. (around $60 \mathrm{~g} \mathrm{~cm}^{-2}$, the weight of $5 \mathrm{~cm}$ steel plus $10 \mathrm{~cm}$ water plus $1 \mathrm{~cm}$ lead plus the layer of boron or $\mathrm{Li}_{2} \mathrm{O}$ ).

Assuming that the effect of a moderator material on neutrons depends only on its hydrogen content, I propose as moderator material an aqueous solution of ammonia saturated at $0^{\circ} \mathrm{C}$ and atmospheric pressure, enclosed in a pressure-tight vessel within this shield. A $7.83 \mathrm{~g} \mathrm{~cm}^{-2}$ layer of this solution should have the same effect on neutrons as a $10 \mathrm{~cm}$ layer of water $\left(C_{\mathrm{n}}=3.2\right)$; the effect on $y$ radiation is assumed to be the same as that of water $\left(C \gamma=\sim 1.5\right.$ per $\left.10 \mathrm{~g} \mathrm{~cm}^{2}\right)$. Further, I propose to replace the $2 \mathrm{~cm}$ layer of lead as well as the boron or $\mathrm{LiO}_{2}$ by moderator liquid. It then becomes possible to incorporate into the shield three layers of moderator liquid of $7.93 \mathrm{~g} \mathrm{~cm}^{-2}$ each (= $23.5 \mathrm{~g} \mathrm{~cm}^{-2}$ ) with a total shielding factor of $C_{\mathrm{n}}=32.7$ or $C_{\mathrm{tot}}=13.7$. Together with the effect of 5-cm steel, protection factors of $C_{\mathrm{n}}=63.5$ and $C_{\mathrm{to1}}=20.9$ result. The addition of $7.83 \mathrm{~g} \mathrm{~cm}^{-2}$ of moderator liquid would make the overall shielding factors $C_{\mathrm{n}}=203$ and $C_{\text {tot }}=34.4$, while the weight would still be well below that of $10-\mathrm{cm}$ steel, accepted by Seifritz et al. as "the classical armour of tanks".

Considering that the intensity of radiation decreases with the square of the distance from the explosion point of the bomb (a factor ignored by Seifritz et al.), the number of tanks $(x)$ which can be stopped by a given bomb will be reduced to $x / C$ by equipping the tanks with a radiation shield of shielding factor $C$ (equal distribution of the tanks over the area presupposed). Thus where one formerly could hope to stop 100 unprotected tanks, a shield of shielding factor $C_{\text {tot }}=20.9$ would reduce the loss of tanks to only 5 , making the neutron bomb unfit as an antitank weapon.

Builders of tanks, keen to keep the weight of their vehicles low, might make it possible to jettison the heavy moderator liquid as soon as contact with the enemy became so close that the use of neutron bombs was unlikely. Diesel fuel might serve as a moderator and hence fuel reserve, making the main fuel tank lighter.

\section{Helsinki, Finland}

ERNST MECKE

\section{Him or her}

SIR - The correspondence on the position of Chinese surnames and the modern practice of hyphenating the following given names which J.A. Irving (Nature 299, 200; 1982) and M.C. McKenna (Nature 300, 212 ; 1982) discuss has raised problems of unusual nomenclatural practice. Dr McKenna states that there "is no longer a problem in English translation because given names are now hyphenated and the second one is not capitalized"'. P.J. Steward (Nature 300, 680; 1982) illustrates that the problem exists, at least in sinicized European names. For foreigners, however, the gender of Chinese names and forenames remains confusing. There is a $\mathrm{Dr}$ Joan Lai-Fook on the staff of my department; she is Chinese. Obviously her gender would be no problem to Dr McKenna as long as he assumed her surname to be "LaiFook". If he assumed that "Joan" was her surname, then it would be logical to assume that she was married to a Dr Joan as LaiFook appears to be a given name. In fact, she is Dr Lai-Fook, and her family surname was Lai, to which the given name Fook was added, and Joan is her given name. There will always be exceptions to every rule.

University of Toronto,

C.S. CHURCHER

Ontario, Canada 